\title{
Tissue $\alpha$-tocopherol status during late fetal and early neonatal life of the guinea-pig
}

\author{
BY FRANK J. KELLY'*, MORTEZA SAFAVI ${ }^{2}$ AND KEVIN H. CHEESEMAN ${ }^{2}$ \\ ${ }^{1}$ Department of Human Nutrition, University of Southampton, Southampton SO9 $3 T U$ and \\ ${ }^{2}$ Department of Biology and Biochemistry, Brunel University, Uxbridge UB8 $3 P H$
}

(Received 20 December 1990 - Accepted 19 June 1991)

\begin{abstract}
The $\alpha$-tocopherol content of a number of different fetal, neonatal and maternal guinea-pig tissues was determined and compared with plasma and erythrocyte $\alpha$-tocopherol values. During late gestation, the fetal liver appears to act as a storage site for $\alpha$-tocopherol, the majority of which is released immediately following birth. In contrast, lung and brain vitamin $E$ levels are relatively constant over the final period of gestation and during early neonatal life. The ontogeny of $\alpha$-tocopherol in brain and lung was similar to that for erythrocytes while plasma $\alpha$-tocopherol content varied considerably and did not accurately reflect tissue $\alpha$-tocopherol status. Surprisingly, fetal and maternal lung $\alpha$-tocopherol concentrations were similar at all time-points considered, whereas fetal liver $\alpha$-tocopherol status was always considerably greater than maternal liver $\alpha$-tocopherol content. These results, if representative of the human fetus, suggest that preterm infants may not have tissue $\alpha$-tocopherol concentrations as low as previously assumed and that during the perinatal period erythrocyte $\alpha$-tocopherol content is a more accurate indicator of tissue $\alpha$-tocopherol concentration than plasma $\alpha$-tocopherol content.
\end{abstract}

Vitamin E: Fetus: Chronic lung disease: Prematurity: Guinea-pig

The newborn infant has low circulating levels of vitamin E (Dju et al. 1958; Mino et al. 1977; Kelly et al. 1990 b). In term neonates, plasma vitamin E concentrations increase rapidly following the feeding of colostrum which contains high concentrations of vitamin E (Ostrea et al. 1986). In sick preterm infants, deprived of colostrum because of intense management of their respiratory insufficiency, plasma vitamin $E$ concentrations rise much more slowly (Bell et al. 1979; Gross \& Gabriel, 1985; Kelly et al. 1990 b). These observations have led a number of workers to suggest that the preterm neonate is born with low concentrations of vitamin $\mathrm{E}$, both circulating and in the tissues, and that is why these infants are particularly sensitive to oxidative stress. In particular, association has been made between deficiency of vitamin $\mathrm{E}$ and chronic lung disease (Ehrenkranz et al. 1982), intraventricular haemorrhage (Chiswick et al. 1983; Speer et al. 1984) and retinopathy of prematurity (Owens \& Owens, 1949; Johnston et al. 1974; Hittner et al. 1981).

Vitamin $\mathrm{E}$ is situated primarily in membranes of cells, where it protects polyunsaturated fatty acids from free-radical-induced oxidative damage (Mason \& Filer, 1947; McCay et al. 1972). Knowledge of membrane vitamin E concentration is, therefore, important when investigating the role of this vitamin in neonatal diseases. Due to ethical and practical difficulties of working with sick preterm infants, little information is available regarding vitamin $E$ status of their tissues. From the few studies available it appears that the human fetus has low tissue concentrations of vitamin $\mathrm{E}$, and these only increase following initiation of feeding at birth (Dju \& Mason, 1952; Dju et al. 1958; Mino et al. 1977).

Recently, Mino et al. (1985) suggested that erythrocyte vitamin E concentration was a

* Present address: Cardiovascular Research, The Rayne Institute, St. Thomas 's Hospital, London SEI 7EH. 
better indicator of tissue vitamin $\mathrm{E}$ status than plasma levels. Based on this assumption, they suggested that the frequency of vitamin $E$ deficiency in premature infants may be lower than previously assumed from assessments of plasma vitamin $E$ status. To examine this hypothesis further, we have assessed the ontogeny of plasma, erythrocyte, liver, lung and brain $\alpha$-tocopherol contents in the guinea-pig during late fetal and early neonatal development. This particular species was studied because we have recently shown that guinea-pig pups can be delivered prematurely by Caesarian section and that these immature animals represent a useful model with which to study chronic lung disease of the newborn (Kelly et al. $1990 a, 1991)$.

\section{METHODS \\ Experimental}

Virgin female Hartley strain guinea-pigs $(500 \mathrm{~g})$ obtained from our own colony in the University of Southampton, were caged in pairs in a room controlled for temperature $\left(22^{\circ}\right)$ and light (06.00-20.00 hours). Animals had free access to food (RGP; SDS, Witham, Essex) and water. The oestrus cycle of each animal was established by daily vaginal smears. Timed pregnancies were achieved by introducing a male into the cage $3 \mathrm{~d}$ before the next ovulation. The date of ovulation in the successfully fertilized cycle was taken as gestational day zero. By this method, normal gestation ends with birth on day 68 .

In those instances where fetal tissues were required, fetuses were delivered by Caesarian section. Operations were performed under halothane anaesthesia maintained with an oxygen-nitrous oxide mixture $(4: 1 \mathrm{v} / \mathrm{v})$. Following double clamping of the uterine vessels, fetuses were removed individually, rapidly dried of placental fluids, weighed and killed by decapitation before the onset of normal breathing. Following decapitation a heparinized blood sample was collected and placed on ice for a short period. Samples were then centrifuged and the plasma was removed and frozen for analysis at a later date. Erythrocytes were washed three times with normal saline $(9 \mathrm{~g}$ sodium chloride/ 1$)$ before resuspension in saline containing $5 \mathrm{~g}$ pyrogallol/l. The lungs, livers and brains of the animals were quickly removed, rinsed in ice-cold saline, blotted dry and weighed. These tissues were kept at $0^{\circ}$ for up to $2 \mathrm{~h}$ before extraction of vitamin $\mathrm{E}$. A number of pregnant dams were allowed to proceed to term and the offspring incorporated in the study at days 2 and 8 post partum. In addition, liver, lung and blood samples were collected from the mothers of all fetal and neonatal animals used in the study.

\section{Vitamin E analysis}

The diet used contained $44.2 \mathrm{mg} \alpha$-tocopherol $/ \mathrm{kg}$ and only traces of other tocopherol isomers. $\alpha$-Tocopherol detected in the blood and tissues represented more than $90 \%$ of the total vitamin $\mathrm{E}$ pool. As a result, in this study only $\alpha$-tocopherol, measured using a highperformance liquid chromatographic (HPLC) technique, is reported. All tissues were homogenized in $0.15 \mathrm{M}$-potassium chloride at $0.2 \mathrm{~g} / \mathrm{ml}$. Homogenates were extracted using the technique of Burton et al. (1985); to $1 \mathrm{ml}$ homogenate, $1 \mathrm{ml}$ sodium dodecyl sulphate ( $50 \mathrm{~mm}$ ), $2 \mathrm{ml}$ absolute ethanol and $1 \mathrm{ml} n$-heptane (HPLC grade) were added. After $2 \mathrm{~min}$ mixing and a brief centrifugation the heptane phase was removed for analysis. $\alpha-$ Tocopherol in plasma $(0.1 \mathrm{ml})$ and erythrocyte suspensions $(0.5 \mathrm{ml})$ was extracted with $0.4 \mathrm{ml}$ and $1.0 \mathrm{ml} n$-heptane respectively. All analyses were performed in duplicate. The separation of $\alpha$-tocopherol by HPLC used a LiChrosorb CN column $(250 \times 4.5 \mathrm{~mm}$; Merck, Poole, Dorset) and a mobile phase of hexane-propan-2-ol $(99: 1, \mathrm{v} / \mathrm{v})$ pumped at $1.5 \mathrm{ml} / \mathrm{min}$. The fluorescence detector was set at $295 \mathrm{~nm}$ excitation and $325 \mathrm{~nm}$ emission; calibration was with an external standard. Recovery of $\alpha$-tocopherol from plasma, 


\section{Table 1. Guinea-pig fetal and neonatal tissue $\alpha$-tocopherol concentrations}

\begin{tabular}{|c|c|c|c|c|c|c|c|c|c|c|c|c|c|}
\hline \multirow[t]{2}{*}{$\begin{array}{l}\text { st-conceptual } \\
\text { (d) ... }\end{array}$} & \multicolumn{2}{|c|}{55} & \multicolumn{2}{|c|}{60} & \multicolumn{2}{|c|}{65} & \multicolumn{2}{|c|}{68} & \multicolumn{2}{|c|}{$\begin{array}{c}70 \\
(2 \mathrm{~d} P \mathrm{P})\end{array}$} & \multicolumn{2}{|c|}{$\begin{array}{c}76 \\
(8 d \mathrm{PP})\end{array}$} & \multirow{2}{*}{$\begin{array}{c}\text { Statistical } \\
\text { significance, } \\
P\end{array}$} \\
\hline & Mean & $\mathrm{SE}$ & Mean & $\mathrm{SE}$ & Mean & $\mathrm{SE}$ & Mean & $\mathrm{SE}$ & Mean & $\mathrm{SE}$ & Mean & $\mathrm{SE}$ & \\
\hline \multirow{6}{*}{$\begin{array}{l}\text { sma } \\
\text { rer } \\
\text { ain } \\
\text { ng } \\
\text { ythrocytes }\end{array}$} & $2 \cdot 6$ & $(0 \cdot 1)$ & $2 \cdot 3$ & $(0 \cdot 2)$ & $3 \cdot 5$ & $(0 \cdot 2)$ & $4 \cdot 3$ & $\left(0^{\cdot} \cdot 9\right)$ & $7 \cdot 9$ & $(1.9)$ & $10 \cdot 1$ & $(1 \cdot 8)$ & 0.0003 \\
\hline & 7.8 & $(1.9)$ & $31 \cdot 1$ & $(7 \cdot 5)$ & $29 \cdot 3$ & $(5 \cdot 8)$ & $25 \cdot 8$ & $(3 \cdot 2)$ & 4.9 & $(0 \cdot 5)$ & $24 \cdot 8$ & $(2 \cdot 8)$ & 0.0008 \\
\hline & $3 \cdot 7$ & $(1 \cdot 0)$ & $10 \cdot 1$ & $(1 \cdot 1)$ & 8.0 & $(1.3)$ & $9 \cdot 0$ & $(1 \cdot 5)$ & $5 \cdot 2$ & $(0 \cdot 4)$ & $12 \cdot 0$ & $(1.6)$ & 0.0015 \\
\hline & $4 \cdot 1$ & $(0 \cdot 3)$ & $7 \cdot 2$ & $(0 \cdot 5)$ & 5.0 & $(1 \cdot 1)$ & $7 \cdot 7$ & $(2 \cdot 0)$ & $5 \cdot 0$ & $(0.3)$ & $8 \cdot 1$ & $(1 \cdot 2)$ & 0.0665 \\
\hline & 1.9 & $(0 \cdot 1)$ & 1.9 & $(0 \cdot 2)$ & 1.9 & $(0 \cdot 1)$ & 20 & $(0 \cdot 1)$ & $1 \cdot 7$ & $(0 \cdot 2)$ & $2 \cdot 5$ & $(0 \cdot 3)$ & 0.0596 \\
\hline & 5 & & 4 & & 4 & & 4 & & 3 & & 6 & & \\
\hline
\end{tabular}

PP, post partum

erythrocytes and tissues by this method was greater than $90 \%, 80 \%$ and $75 \%$ respectively, and the coefficient of variance less than $5 \%$ for all measurements.

\section{Triacylglycerol analysis}

The heptane extracts used for tocopherol analysis were also used for determination of the triacylglycerol content of the liver. A portion was brought to dryness with a stream of nitrogen and the lipid saponified with ethanolic potassium hydroxide. After neutralization, samples were analysed using a triacylglycerol test kit (Cat. no. 240052; Boehringer Mannheim, Lewes, E. Sussex).

\section{Statistical analysis}

Results were analysed by one-way analysis of variance (ANOVA). Correlation coefficients were calculated by linear regression analysis. Values of $P<0.05$ were considered significant.

\section{RESULTS}

At the earliest considered time-point in gestation (55 d), plasma $\alpha$-tocopherol concentration was $2.6 \mathrm{nmol} / \mathrm{ml}$ (Table 1). From $60 \mathrm{~d}$ gestation, plasma $\alpha$-tocopherol increased steadily, approximately doubling over the final $8 \mathrm{~d}$ of gestation to $4 \mathrm{nmol} / \mathrm{ml}$. Between birth and day 2 post partum plasma $\alpha$-tocopherol concentration doubled again to $8 \mathrm{nmol} / \mathrm{ml}$, and by $8 \mathrm{~d}$ post partum plasma $\alpha$-tocopherol had increased further to $10 \mathrm{nmol} / \mathrm{ml}$ (Table 1). Maternal plasma $\alpha$-tocopherol concentrations were always more constant at all time-points considered, ranging between 2 and $3 \mathrm{nmol} / \mathrm{ml}$ at all ages considered (values not shown).

Liver $\alpha$-tocopherol increased nearly 4 -fold between day 55 and day 60 of gestation, rising from 8 to over $30 \mathrm{nmol} / \mathrm{g}$. Over the final $8 \mathrm{~d}$ of gestation liver $\alpha$-tocopherol concentration remained relatively constant. Following birth, however, liver $\alpha$-tocopherol concentration fell markedly to $5 \mathrm{nmol} / \mathrm{g}$ tissue at 2 d post partum before increasing again to $24.8 \mathrm{nmol} / \mathrm{g}$ tissue by day 8 post partum. The fetal liver has a distinctly fatty appearance during the last $8 \mathrm{~d}$ of gestation, and by way of comparison with $\alpha$-tocopherol, hepatic triacylglycerol concentrations were also determined. Liver triacylglycerol displayed a remarkedly similar profile to liver $\alpha$-tocopherol, with a similar dramatic rise between $55 \mathrm{~d}(25.4 \mathrm{mg} / \mathrm{g}$ liver $)$ and $60 \mathrm{~d}$ gestation $(95.7 \mathrm{mg} / \mathrm{g}$ liver) and a precipitous fall around birth ( $12.5 \mathrm{mg} / \mathrm{g}$ liver, day 2$)$. 


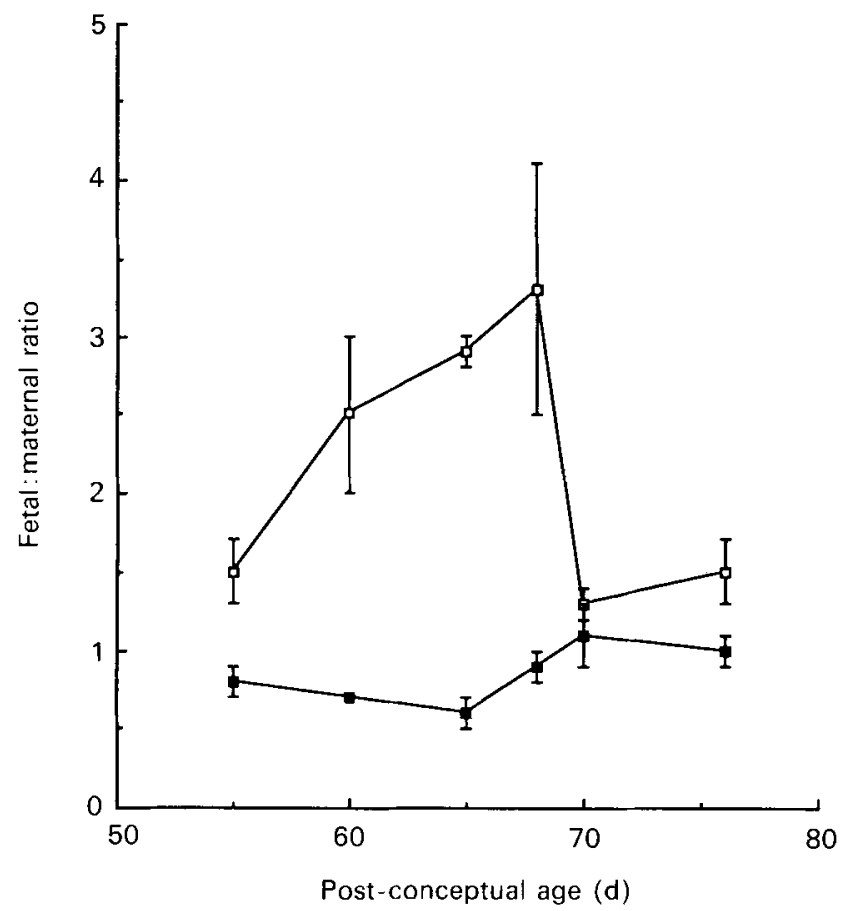

Fig. 1. Liver $(\square)$ and lung ( $\mathbf{0}$ ) fetal:maternal tissue vitamin $\mathbf{E}$ ratios during late fetal and early neonatal development. Results are expressed as means with their standard errors represented by vertical bars.

In contrast to the large changes in liver $\alpha$-tocopherol concentration before and following birth, the concentration of $\alpha$-tocopherol in brain, lung and erythrocytes remained relatively constant (Table 1). Only brain showed a significant increase in $\alpha$-tocopherol content between 55 and $60 \mathrm{~d}$ gestation and then again between 2 and $8 \mathrm{~d}$ post partum. Linear regression analysis revealed a positive correlation between erythrocyte $\alpha$-tocopherol content and brain $(r 0.41, P=0.047)$ and lung $(r 0.38, P=0.059) \alpha$-tocopherol content. No correlation was observed between plasma $\alpha$-tocopherol content and brain, lung or erythrocyte $\alpha$-tocopherol concentration. Liver $\alpha$-tocopherol content did not correlate with either plasma or erythrocyte $\alpha$-tocopherol.

When the $\alpha$-tocopherol concentrations in fetal and corresponding maternal tissues were compared it was found that concentrations of $\alpha$-tocopherol in the fetal liver were consistently higher than maternal levels, with the maximum difference (3-fold) seen just before birth (Fig. 1). On the other hand, fetal and maternal lung vitamin E concentrations were approximately equal at all time-points considered, as indicated by a fetal:maternal ratio of 1 (Fig. 1).

\section{DISCUSSION}

$\alpha$-Tocopherol is now widely accepted to be the body's most important lipid-soluble antioxidant (Burton \& Ingold, 1986). It scavenges free radicals, preventing oxidative injury to polyunsaturated fatty acids in cellular membranes, thus preserving the structure and functional integrity of subcellular organelles (Tappel, 1962).

It has previously been suggested, based on plasma concentrations of $\alpha$-tocopherol, that the preterm infant is deficient in $\alpha$-tocopherol (Bell et al. 1979; Gross \& Gabriel, 1985). The value of using plasma $\alpha$-tocopherol concentrations in this manner is not clear, since $\alpha$ tocopherol is carried in the blood in the lipoprotein fraction and, therefore, plasma levels 
reflect lipid levels and give little information regarding the tissue concentrations of $\alpha$ tocopherol (Muller, 1987). Indeed, the findings of the present study would suggest that plasma $\alpha$-tocopherol status does not accurately reflect $\alpha$-tocopherol status over the perinatal period for the brain or the lung, and is an especially poor indicator of the $\alpha$-tocopherol status of the liver.

Following birth in the guinea-pig, plasma $\alpha$-tocopherol concentration, unlike tissue $\alpha$ tocopherol concentrations, increased considerably. This was most likely due both to release of $\alpha$-tocopherol stores from the liver and to the intake of large amounts of $\alpha$-tocopherol in the colostrum (Ostrea et al. 1986). Erythrocyte $\alpha$-tocopherol levels on the other hand were reflective of lung and brain $\alpha$-tocopherol concentration; small decreases in $\alpha$-tocopherol were observed soon after birth followed by a subsequent increase by day 8 . These results suggest that erythrocyte $\alpha$-tocopherol status is a much better index of tissue $\alpha$-tocopherol content, at least in respect of lung and brain, while the liver appears to be an exception, for reasons discussed later. In a previous study in our laboratory low erythrocyte $\alpha$-tocopherol levels were observed in preterm infants up to 7 weeks following birth (Kelly et al. 1990 b). If the findings of the present study are applicable to human infants it would appear that lung and brain $\alpha$-tocopherol concentrations were also low in these infants over this period.

In the case of the liver there is a postnatal decrease in $\alpha$-tocopherol content large enough to suggest that the liver acts as a depot, releasing $\alpha$-tocopherol into the blood immediately following birth. This observation agrees well with previous findings in the pig (Schlotke et al. 1978) and rat (Butcher \& Roberts, 1981). The time-courses of change in hepatic $\alpha-$ tocopherol and triacylglycerol contents are remarkably similar, but we do not yet have evidence that they are physically associated in the liver. We are currently investigating the subcellular location of $\alpha$-tocopherol in the liver over a similar time-course. Small decreases in the $\alpha$-tocopherol concentrations of the lung and brain following birth were also noted. These findings, taken in conjunction with the fact that these neonatal animals were receiving large quantities of $\alpha$-tocopherol from the mothers' colostrum, may indicate an increased utilization of $\alpha$-tocopherol in these tissues following birth. This point could probably only be clarified by studies on $\alpha$-tocopherol turnover.

An important finding of the present study was that the levels of $\alpha$-tocopherol in fetal tissues are not as low as might have been expected. It has been generally assumed, based on plasma values, that tissue $\alpha$-tocopherol levels are low. However, comparing the concentration of $\alpha$-tocopherol in the tissues of the fetus with those in the tissues of the corresponding mothers we found that fetal liver $\alpha$-tocopherol levels are actually always higher than those in the maternal liver, and fetal lung values are approximately the same as those in the maternal lung. This finding argues against a role for $\alpha$-tocopherol deficiency per se in the pathogenesis of chronic lung disease in the prematurely born neonate. Oxidative stress may still, however, be an important factor, due to the relatively low levels of antioxidant enzymes and glutathione in the tissues of the prematurely born animal (Rickett \& Kelly, 1990).

In summary, we have examined the ontogeny of vitamin E accumulation in plasma and a number of different fetal and neonatal tissues during perinatal development in the guineapig. Significant $\alpha$-tocopherol storage occurs in fetal liver over the final period of gestation and considerable amounts of this appear to be utilized or released immediately following birth. By $8 \mathrm{~d}$ post partum liver $\alpha$-tocopherol stores are mostly replenished. Plasma $\alpha-$ tocopherol levels remain relatively low until birth, at which time there is a rapid increase, probably due both to the release of liver $\alpha$-tocopherol stores and to high levels of $\alpha$ tocopherol present in colostrum. Lung and brain $\alpha$-tocopherol contents remain relatively constant over the final period of gestation and during early neonatal life. Similar observations were made in erythrocytes, indicating that the erythrocyte $\alpha$-tocopherol 
content is a much more accurate indicator of tissue $\alpha$-tocopherol content than plasma $\alpha$-tocopherol concentration.

This study was supported in part by the Agricultural and Food Research Council.

\section{REFERENCES}

Bell, E. F., Brown, E. J., Milner, R., Sinclair, J. C. \& Zipursky, A. (1979). Vitamin E absorption in smail premature infants. Pediatrics 63, 830-832.

Burton, G. W. \& Ingold, K. U. (1986). Vitamin E: Application of the principles of physical and organic chemistry to the exploration of its structure and function. Accounts on Chemical Research 19, 194-201.

Burton, G. W., Webb, A. \& Ingold, K. U. (1985). A mild, rapid and efficient method of lipid extraction for use in determining vitamin E/lipid ratios. Lipids 20, 29-39.

Butcher, J. R. \& Roberts, R. J. (1981). $\alpha$-Tocopherol (vitamin E) content of lung, liver and blood in the newborn rat and human infant: Influence of hyperoxia. Pediatrics $\mathbf{9 8 ,} 806811$.

Chiswick, M. K., Johnston, M., Woodhall, C., Gowland, M., Davies, J., Toner, N. \& Sims, D. G. (1983). Protective effect of vitamin $\mathrm{E}$ against intraventricular hemorrhage in premature babies. British Medical Journal 287, 81-84.

Dju, M. Y. \& Mason, K. K. (1952). Vitamin E (tocopherol) in human fetuses and placentae. Etudes Néo-natales 1, 49-62.

Dju, M. Y., Mason, K. E. \& Filer, L. J. (1958). Vitamin E (tocopherol) in human tissues from birth to old age. American Journal of Clinical Nutrition 6,50-60.

Ehrenkranz, R. A., Bonta, B. W., Ablow, R. C. \& Warshaw, J. B. (1982). Amelioration of bronchopulmonary dysplasia after vitamin A administration. New England Journal of Medicine 29, 564-569.

Gross, S. J. \& Gabriel, E. (1985). Vitamin E status in preterm infants fed human milk or infant formula. Journal of Pediatrics 106, 635-639.

Hittner, H. M., Godio, L. B., Rudolph, A. J., Adams, L. H., Garcia-Prats, J. A., Friedman, Z., Kavtz, J. A. \& Monaco, W. A. (1981). Retrolental fibroplasia: efficacy of vitamin E in a double-blind clinical study of preterm infants. New England Journal of Medicine 305, 1365-71.

Johnson, L., Schaffer, D. \& Boggs, T. (1984). The premature infant, vitamin E deficiency and retrolental fibroplasia. American Journal of Clinical Nutrition 27, 1158-1173.

Kelly, F. J., Rickett, G., Hunt, G., Town, I., Holgate, S. \& Postle, T. (1990a). Biochemical maturation of the guinea pig lung and survival following premature delivery. International Journal of Biochemistry 73, 693-697.

Kelly, F. J., Rodgers, W., Handel, J., Smith, S. \& Hall, M. A. (1990 b). 'Time course of vitamin E repletion in the premature infant. British Journal of Nutrition $\mathbf{6 3}, 631-638$.

Kelly, F. J., Town, I., Phillips, G., Holgate, S., Roche, W. \& Postle, T. (1991). The preterm guinea pig: A mode: for the study of neonatal lung disease. Clinical Science 81, 439-446.

McCay, P. B., Pfeifer, P. M. \& Stipe, W. H. (1972). Vitamin E protection of membrane lipids during electron transport functions. Annals of the New York Academy of Sciences 203, 6273.

Mason, K. E. \& Filer, L. J. (1947). Intertelationships of dietary fat and tocopherols. Journal of the American Oil Chemists' Society 24, 240242.

Mino, M., Kitagawa, M. \& Nakagawa, S. (1985). Red blood cell tocopherol concentrations in a normal population of Japanese children. American Journal of Clinical Nutrition 41, 621-628.

Mino, M., Nishino, H., Yamaguchi, T. \& Hayashi, M. (1977). Tocopherol level in human fetal and infant liver. Journal of Nutritional Science and Vitaminology 23, 63-69.

Muller, D. P. R. (1987). Free radical problems of the newborn. Proceedings of the Nutrition Society 46, 69-75.

Ostrea, E. M., Balun, J. E., Winkler, R. \& Porter, T. (1986). Influence of breast-feeding on the restoration of the low serum concentration of vitamin $\mathrm{E}$ and $\beta$-carotene in the newborn infant. American Journal of Obstetrics and Gynecology 154, 1014-1017.

Owens, W. C. \& Owens, E. U. (1949). Retrolental fibroplasia in premature infants. II. Studies on the prophylaxis of the disease: the use of alpha tocopherol acetate. American Journal of Ophthalmology 32, 1631-1637.

Rickett, G. W. \& Kelly, F. J. (1990). Developmental expression of antioxidant enzymes in guinea pig lung and liver. Development 106, 331 336 .

Schlotke, B., Busch, L. \& Koch, F. (1978). Untersuchungen zum einfluß vitamin-E-armer ernährung bei sauen während der gravidität auf den vitamin-E-status der ferkel in der neugeborenenphase (Studies on the effect of vitamin $\mathrm{E}$ deficient diet in sows during pregnancy on the vitamin E status of newborn piglets). Zentralblatt für Veterinärmedizin 25, 474-478.

Speer, M. E., Blifeld, C., Rudolph, A. J., Chadda, P., Holbein, B. \& Hittner, H. (1984). Intraventricular hemorrhage and vitamin $E$ in the very low birth weight infant: evidence for efficacy of early intramuscular vitamin E administration. Pediatrics 74, 1107-1112.

Tappel, A. L. (1962). Vitamin E as the biological lipid antioxidant. Vitamins and Hormones 20, 493-510. 